\title{
A educação como elemento de reconstrução nacional: o caso da Nicarágua Sandinista.
}

\author{
Gerson Wasen Fraga"
}

RESUMO

A finalidade deste artigo é oferecer uma breve análise da forma com que a educação pode se constituir em elemento de reconstrução de uma nação. Para tanto, aborda-se o caso da Cruzada Nacional de Alfabetização efetuada pelo governo Sandinista da Nicarágua após sua ascensão ao poder em 1979. Destacamos aqui seus objetivos, alguns aspectos de sua organização, abordando brevemente ainda seus principais pressupostos teóricos.

Palavras-chave: América Latina, Nicarágua, Sandinismo, Educação, Alfabetização.

\section{Introdução}

Em julho de 1979, a Frente Sandinista de Libertação Nacional (FSLN), com apoio da população, de setores burgueses e de parte expressiva da opinião pública internacional, pôs fim à "dinastia Somoza", um regime ditatorial que por mais de quarenta anos dominou a Nicarágua, transformando-a em um verdadeiro reduto a serviço dos interesses do capital internacional. A herança deste regime ficava expressa no colapso do setor agrário - base econômica da nação -; no parque industrial destruído, quando não sabotado pelos próprios empresários ligados à figura de Somoza; nas cidades, seriamente danificadas pelos bombardeios aéreos ordenados pelo ditador em sua luta para manter-se no poder; na carência de profissionais liberais ou técnicos, que em grande parte provinham das classes dominantes e que, portanto, não permaneceram no país, privando assim a população dos seus serviços, o que se refletiu em áreas como saúde, educação, ou (re)construção civil; no despreparo de

* Doutorando em História pelo PPGH/UFRGS. Email: gwraga@terra.com.br. 
combatentes que após anos lutando em regiões montanhosas, tinham agora diante de si a tarefa de gerir um Estado.

E havia $52 \%$ da população no analfabetismo. ${ }^{1}$

Identificado como o problema central a ser atacado para levar a cabo a reconstrução do país, o analfabetismo passou a ser alvo de uma verdadeira cruzada nacional, envolvendo diretamente um contingente estipulado em 180.000 alfabetizadores (ASSMAN, 1981, p. 71). Após 5 meses, este índice havia caído para $12,9 \%$, conforme os dados oficiais do governo nicaragüense.

Este artigo visa oferecer um breve entendimento da forma como se deu a Cruzada Nacional de Alfabetização (CNA), apontando alguns de seus conceitos, objetivos e estratégias, vislumbrando o papel que passou a ser dado à educação em um contexto de transformação social, onde o acesso de um povo às letras foi entendido como um elemento fundamental na reconstrução não apenas material, mas também "espiritual" de uma nação.

\section{A educação da inclusão social e do cotidiano.}

A Nicarágua em fins dos anos 1970 poderia ser classificada como um pequeno peão no jogo da Guerra Fria; uma República menor situada dentro da área de influência norte-americana que deveria ser mantida longe de maus exemplos, como o patrocinado por sua maior vizinha insular. De semelhante modo ao que então ocorria em larga escala na América Latina, seu governo tinha, entre suas principais preocupações, manter-se permanentemente dentro de uma postura simpática aos olhos dos Estados Unidos. Assim, não somente os principais interesses da população ficavam relegados a um segundo plano, mas igualmente a economia do país era organizada de modo a favorecer os interesses externos, não havendo maiores preocupações quanto à educação ou outros investimentos sociais.

Desta forma, sob o período somozista, um analfabetismo que atingia mais de metade da população se fazia acompanhar de uma economia calcada sobre latifúndios voltados para exportação e sob o controle de uma oligarquia marcada por fortes laços de parentesco.

Esta realidade apresentava uma lógica tão simples quanto pragmática.

1 Conforme censo efetuado em outubro de 1979. 
A mão-de-obra analfabeta é sabida e historicamente uma mão-de-obra dócil, que valoriza a atividade manual como a única digna de ser considerada um verdadeiro trabalho. Ao mesmo tempo, práticas patriarcais são encaradas como naturais nas relações produtivas, ficando eventuais conflitos inter-classes anestesiados a partir destas relações. Em outras palavras, uma economia de exclusão demandava e gerava uma educação de exclusão. Sobre este período e sobre 0 tratamento nele dado à educação, comenta Fernando Cardenal:

Entoces es bien importante comprender que en esta educación el analfabetismo es un fenómeno buscado, mantenido, para poder mantener las estructuras de explotación. No es por falta de dinero que aquí antes no se hizo una Cruzada Nacional de Alfabetización (CARDENAL, In: ASSMANN, 1981, p. 29).

Assim, a partir da ascensão dos sandinistas ao poder, a educação deveria passar por uma profunda transformação, conforme a nova realidade que se apresentava àquela nação centro-americana. A necessidade de técnicos, que esbarrava no grande contingente de analfabetos, exigia que homens e mulheres passassem agora por outra revolução, de caráter pessoal, objetivando sua transformação no agente histórico que nunca foram. Estes deveriam ser agora incorporados no urgente processo de reconstrução do país. Para tanto, era inicialmente necessário revisar os planos educacionais até então implantados e que tão poucos resultados tiveram. Tais planos, seguindo uma tendência até hoje verificada na América Latina, eram muitas vezes importados de organismos internacionais, visando a formação de profissionais não para o suprimento de necessidades locais, mas para a execução dos projetos igualmente elaborados por estes organismos, conforme os anseios do grande capital internacional para aquela região.

Deste momento em diante, a educação deveria ser pensada de outra forma. Não mais a partir de noções concebidas em gabinetes, mas da realidade, do cotidiano e das necessidades nicaragüenses. Pode-se argüir que através desta concepção, o povo estaria sendo colocado sob um objetivo político, a serviço de um grupo que naquele momento promovia um processo revolucionário. Esta leitura é correta. Tão correta quanto o fato de que a partir da Cruzada de Alfabetização, metade de uma nação deveria adquirir uma consciência política que até então lhe era vedada, passaria a ter noção de seu 
papel histórico, a produzir não mais exclusivamente para o grande capital, mas para um conjunto designado como sociedade. Paralelamente, sua estrutura social arcaica não mais seria vista como algo imutável. Conforme o então comandante Bayardo Arce Castaño, em conferência proferida em 15 de novembro de 1979:

Hablemos entoces de uma Educación que tiene que partir del conocimiento objetivo de nuestra realidad, que tiene que partir del análisis frío de las realidades socio-economicas de Nicarágua, que tiene que estar clara del proyecto político de la Revolución, que tiene que estar compenetrada de las perspectivas de desarrollo de nuestro país para programar la actividad que genere esto recursos humanos que estamos necessitando (CASTAÑO, In: ASSMANN, 1981, p. 20).

Desta forma, o governo revolucionário sandinista, através da educação, partindo de seus níveis mais elementares, buscava suprir necessidades técnicas para a reconstrução nacional e despertar a consciência popular para o momento de transição que se operava no campo político. Em consequiência, os governantes não se localizariam mais em um patamar inatingível para a população, mas compartilhariam com esta de objetivos comuns através da construção de uma nova sociedade e de uma educação democratizada. Segundo PIVA e PIVA (1986, p. 64), "um processo revolucionário é altamente pedagógico. A educação torna-se, portanto, o elo principal de ligação entre a nova classe dirigente e a população, que, juntas, formam um novo bloco histórico no poder".

\section{Os 8 objetivos da Cruzada Nacional de Alfabetização ${ }^{2}$}

Quais eram os objetivos da Cruzada Nacional de Alfabetização? 0 que pretendia e quais as conseqüências que se esperava desta verdadeira revolução educacional que se fomentava?

De forma sucinta, seus objetivos eram:

1- Buscar o fim da alta taxa de analfabetismo existente entre a população.

2-Promover a tomada de consciência por parte do indivíduo de sua atividade, de sua condição de sujeito histórico, capaz de realizar transformações

\footnotetext{
2 Estes oito objetivos são especificados por Fernando Cardenal e encontram-se compilados na obra de Assmann. Estão apresentados aqui de forma sintetizada.
} 
no meio em que vive.

3-Assentar as bases para a instauração de um processo permanente de alfabetização de adultos, proporcionando-lhe inclusive 0 acesso ao ensino superior quando assim o desejasse.

4-Promover o fortalecimento das organizações populares. Tais organizações deveriam enviar para a cruzada seus melhores quadros, que assim teriam, através do trabalho neste processo, um período de formação e crescimento pessoal.

5-Promover a conscientização dos jovens, uma vez que estes se constituíam na força básica de efetivação da CNA.

6-Formar uma identidade comum entre a população, uma vez que 0 país encontrava-se extremamente dividido em uma série de dualidades (campocidade, Atlântico-Pacífico, trabalho manual-trabalho intelectual).

7-Difundir hábitos de higiene e saúde. Através desta ação, esperava-se reduzir um índice de mortalidade infantil que beirava 15\%, mas que certamente era bem mais elevado em regiões periféricas.

8-Elaborar uma coleção da flora, da fauna e da geologia nicaragüense, levantar cantos, contos e lendas típicas, levantamentos de sítios arqueológicos, elencando um patrimônio cultural capaz de caracterizar a nação e com o qual sua população pudesse se identificar. Da mesma forma, seriam colhidas duas mil gravações, dois mil relatos sobre o processo revolucionário, com pessoas escolhidas nos mais diversos recantos do país, a fim de organizar-se um verdadeiro museu de história oral da luta pela liberdade do povo nicaragüense.

Para além de uma etapa do processo revolucionário, a CNA era um importante passo dentro da continuidade e do aprofundamento da revolução, dado o caráter político conferido à educação pelos sandinistas. Neste momento, onde os lápis substituíam os fuzis, esperava-se que os brigadistas não apenas cumprissem com sua função de alfabetizadores, despertando a consciência da população para o processo no qual estava inserida, mas que também tivessem sua consciência despertada para a importância de seu papel naquele momento. Esperava-se aqui pela formação de novas lideranças, a fim de garantir-se 0 futuro da revolução.

\section{Uma revolução freireana.}


0 embasamento teórico que fundamentava esta perspectiva revolucionária de educação assentava-se sobre os ensinamentos e pressupostos desenvolvidos por Paulo Freire. ${ }^{3}$ Entendendo a educação como instrumento de reflexão e ação sobre a realidade, visava-se dar ao educando condições de perceber sua condição de oprimido e de identificar as formas por que se dava esta opressão.

Assim, o alfabetizando não só aprende a ler e a escrever como também passa a ter uma visão crítica da realidade que o cerca. Passa (...) da condição de objeto para a de sujeito dessa realidade. A etapa seguinte costuma ser o engajamento nas lutas de caráter libertador e coletivo, pelo oprimido, contra o opressor (GALVÃO et al., p. 70).

0 processo de alfabetização pressupunha o uso de frases chaves, construindo palavras e idéias a partir da realidade experimentada pelo povo. Lembremos aqui que esta nova realidade não se constituía em via de mãoúnica, pois que, através da troca de experiências, também o alfabetizador passaria um processo de aprendizagem, através da vivência na casa do educando, em contato com suas necessidades e com sua cultura. Este processo é explicitado nas declarações de um universitário, voluntário engajado na CNA, ao ser questionado sobre os elementos do método Paulo Freire utilizados na cartilha:

Cada lição começa com a discussão de uma fotografia e com uma frase-chave, que faz referência a um aspecto principal da foto. 0 processo de conhecimento de todos os participantes deve ser referido a esta frase-chave. Cada frase contém um conceito-básico, o qual permite a formação de sílabas. A isto segue a formação de palavras. Após são apresentadas novas palavras e, mais tarde, o próprio alfabetizado deverá formulá-las. Eu esforcei-me por escrever, no quadro negro, sílabas e conceitos, com os quais o grupo pudesse mais facilmente completar palavras. (...) Enfim, na primeira lição, aprendemos as vogais, na segunda, começamos a forçar sílabas e, aos poucos, as idéias iam penetrando, desde o livro até a cabeça daquela gente. Na cartilha, a palavra Fonseca ( $u m$ dos líderes da revolução) devia ter as sílabas sublinhadas. Após encetamos o estudo das consoantes, como ligar "s" com as vogais etc. No fim da lição, já se tentava formular pequenas

3 Principalmente a partir de sua clássica obra "Pedagogia do Oprimido". 
palavras. (ALBERT, In: ZIMMER, 1987, p. 129-32).

Quanto à organização do ensino, este teria em seu nível básico uma duração de 9 anos (seis no primário e mais três no secundário), gratuitamente, visando oferecer o mesmo padrão de qualidade para todos os alunos, e ainda proporcionando assistência a escolar, em especial aos filhos de camponeses, a fim de que fosse evitada a evasão. Também a cargo do Estado ficavam as escolas infantis (pré-escolas) e as escolas de especiais, pois era esperado que uma certa parcela de crianças apresentasse dificuldades diversas no aprendizado pelos mais amplos fatores. No entanto, um aspecto receberia ênfase extraordinária por parte do Estado, devido principalmente ao caráter agrícola da economia nicaragüense: o ensino agrário e veterinário. Os professores destas áreas seriam objeto de atenção e formação especiais, pois atuariam tanto entre a juventude como entre uma população adulta, desenvolvendo o trabalho de reconstrução. Por fim, os educadores passariam por um processo de valorização, uma vez que sua atividade era considerada como a mais revolucionária de todas, cabendo a eles afinar as mentalidades ao novo contexto, em um trabalho que poderia decidir futuramente os caminhos da nação e de seu povo.

\section{O Educador e o educando}

Qual o perfil dos educadores envolvidos na CNA? Quais dentre eles deveriam ser mandados para as regiões mais distantes? Ao mesmo tempo, como caracterizar a população a ser alfabetizada?

0 verdadeiro exército de alfabetizadores seria composto por estudantes, donas de casa, operários, enfim, por todos aqueles que soubessem ler e escrever e que se dispusessem a se engajar na CNA. Pessoas por vezes sem nenhuma experiência pedagógica, o que requereria a elaboração de um método capaz de ser aplicado conjuntamente por este vasto grupo. Todavia, para as regiões mais afastadas do país, seriam designados unicamente estudantes que estivessem no mínimo na rede secundária, uma vez que os operários eram necessários nas zonas urbanas a fim de que a produção não fosse paralisada. Muitos desies jovens alfabetizadores que se deslocavam para o campo tinham 13 ou 14 anos e necessitavam, inclusive, da autorização dos pais para se engajarem na 
Cruzada. Sua área de atuação, conforme as distâncias a serem percorridas, poderia se resumir tão somente a uma casa, se esta fosse muito afastada de qualquer outro núcleo familiar. Sua integração à vida camponesa se daria de forma orgânica (promovendo a conscientização sobre a realidade nacional expressa no quinto objetivo da CNA), vivenciando a realidade da família que o recebeu. Sobre isto, fala Alicia Chacon, encarregada do Departamento de Imprensa da Campanha de Alfabetização:

O brigadista que vai ao campo já sabe que vai trabalhar gratuitamente por quatro meses, que vai viver na casa do campesino, se supõe que as famílias dos campesinos sejam numerosas, então ele vai viver na casa do campesino como parte da família, vai se integrar à vida da casa, vai alfabetizar supondo que também hajam crianças, homens e mulheres. Também sabe que o campesino levanta muito cedo para trabalhar. Então o campesino vai ter a colaboração do brigadista que vai trabalhar junto. 0 que nós também queremos é que haja esta integração, por isso ele também vai levantar cedo. 0 que nós queremos é que ele se integre à vida do campesino, conheça sua miséria, saiba como era explorado pelos latifundiários (CHACON, In: CARUSO, 1980, p. 52).

Evidentemente, a ação destas pessoas em áreas afastadas corria 0 permanente risco de sofrer represálias por parte dos grupos paramilitares contrários ao movimento Sandinista. Não cabia, porém, aos "brigadistas" (os educadores enviados para áreas distantes) portarem armas para sua defesa pessoal, ficando sua segurança a cargo de membros do Exército Popular Sandinista. Cabe ainda destacar que cerca de $60 \%$ deste grupo era constituído por mulheres.

Já os alfabetizandos, conforme investigações preliminares (ASSMANN, 1981, p. 64), poderiam ser separados em dois grupos básicos: adultos e adolescentes. Os primeiros poderiam ser caracterizados como sendo possuidores de um amplo vocabulário, de uma cultura advinda de suas lutas e de seu trabalho, com costumes e superstições arraigadas, conhecedores de sua realidade imediata, possuidores de uma memória ampla, e, dado curioso, possuidores de certas deficiências, como visuais, auditivas, musculares, entre outras. Já os adolescentes seriam caracterizados como amadurecidos de maneira precoce, 
devido as suas duras condições de vida que levavam, na qual adquiriram um alto grau de consciência política, desenvolvida através da participação na luta de libertação.

\section{A pós-alfabetiração e 0 auxilio internacional}

Conforme o terceiro ponto arrolado entre os objetivos da CNA, àqueles que foram recém alfabetizados deveria ser proporcionado um acompanhamento posterior, a fim de que os mesmos consolidassem o seu aprendizado. Para tanto, foram constituídos os "Coletivos de Educação Popular" (CEP), integrando preferencialmente entre três e doze pessoas, separados em duas classes: os recém alfabetizados, e aqueles que, por algum motivo, não tivessem terminado as atividades propostas na cartilha de leitura e escrita. Estes coletivos teriam um coordenador, escolhido preferencialmente (mas não de forma obrigatória) entre os alfabetizadores mais destacados no período da Cruzada. Este coordenador estaria por sua vez subordinado a um Promotor Popular, função a ser desempenhada por alguém "um pouco mais avançado em estudos", ou que dispusesse de um histórico de experiências políticas e organizativas. Ao Promotor cabia o trabalho de assessorar um conjunto de CEP's, orientando seus trabalhos e dando os aportes necessários. Paralelamente a isto, foram constituídas Comissões Municipais, que organizariam, juntamente com os promotores, oficinas semanais, a fim de avaliar e orientar o trabalho desenvolvido pelos coordenadores.

Por trás desta organização hierárquica, residiam cinco objetivos básicos 4 : garantir o término do caderno de leitura e escrita; criar os Coletivos de Educação Popular como uma continuidade das unidades de alfabetização anteriores (0 que pressupõe um aprimoramento da consciência de organização social); reforçar o desenvolvimento da consciência políitca; impedir a perda do hábito de ler e escrever; mantendo a motivação por este hábito; bem como dar continuidade ao trabalho com as operações matemáticas básicas.

Pretendia-se assim dar mais um passo na erradicação do analfabetismo,

\footnotetext{
4 Objetivos arrolados no documento Carta al alfabetizador, aqui apresentados de forma sintetizada. Compilado na obra de ASSMANN, 1981, p. 286.
} 
incorporando de maneira efetiva os educandos ao processo revolucionário. Buscava-se ainda, através da aquisição de novos conhecimentos, aumentar 0 grau de produtividade nacional, objetivo que seria atingível após o desenvolvimento de um certo grau de educação. Conforme Alicia CHACON (1980, p. 56), "a alfabetização é um fato político, é um compromisso revolucionário, eles devem integrar-se às organizações de massa, conhecer novas técnicas agrícolas, tudo isso. Antes, por exemplo, os campesinos nem sabiam que existia um código do trabalho".

A busca de soluções para problemas imediatos em políticas de longo prazo deve ser entendida dentro da busca, por parte do governo sandinista, de soluções adaptadas a sua realidade, bem como da construção de uma estrutura educacional que consolidasse 0 processo revolucionário. Levada a cabo inicialmente apenas com a força de sua população, a CNA logo despertou a solidariedade e o interesse por parte de outros povos, bem como a atenção de organismos internacionais. Com efeito, educadores de diversos lugares do mundo acorreram à Nicarágua, não apenas com o intuito de engajar-se no processo revolucionário, mas também visando observar in loco 0 desenvolvimento de seu projeto educacional. Este auxílio não proveio apenas de países de fala hispânica, havendo inclusive voluntários do continente europeu. Ao mesmo tempo, ao contrário do que ocorrera quando da Revolução Cubana 20 anos antes, a UNESCO não esperou o flagrante sucesso da campanha para solicitar a ajuda internacional, demonstrando assim sua confiança em que outro povo latino americano rompesse os grilhões da ignorância. (CORTÁZAR, 1987, p. 35).

\section{Conclusão}

Pouco mais de dez anos após terem ascendido ao poder, através de um processo revolucionário no qual foi indispensável o apoio da população civil, os sandinistas se viram afastados deste posto pela decisão desta mesma população - desta vez expressa nas urnas, elegendo a candidata oposicionista Violeta Chamorro para a presidência da Nicarágua. Embora não tenham atingido seus objetivos militares de forma imediata, a ação dos Contras (grupo contrarevolucionário apoiado e financiado pelo governo norte-americano) acabou 
atingindo seu intento por vias indiretas, em uma verdadeira vitória gerada de uma fragorosa derrota.

Diez años de guerra civil, cincuenta mil muertos en ambos bandos, una economia destrozada - en gran medida por las necessidades militares sandinistas para impedir el triunfo de la "contra" - y un estado general de cansancio provocaran lo que, sin duda, es una nueva página en la historia de Nicaragua (YEVES, 1990, p. 251).

Sem dúvida, inúmeras lições são passiveis de serem tiradas de um período tão rico em idealismos e novas experiências. Limitando-nos ao nosso objeto principal, devemos atentar para os resultados obtidos por um programa criado a partir da observação das necessidades empíricas de um povo, um programa que contou com o experimentalismo e com a criatividade, mas que também dispensou luxos e caprichos para libertar metade de uma nação da escravidão causada pela ignorância. 0 resultado da Cruzada Nacional de Alfabetização, reduzindo o índice de analfabetismo de $52 \%$ para $12,9 \%$ em menos de meio ano é ainda hoje exemplar, seja por sua eficácia, seja pelo grau de comprometimento e consciência que despertou.

Ainda há muito que aprender com o exemplo da pequena república da América Central.

\section{Referênciss}

ALBERT, Maria Theresia, A Campanba de Alfabetização com Processo de Conscientização do Povo, In: ZIMMER, Jürgen (org.). Pedagogia da Liberiação: ensino na Nicarágua, Feplam: Porto Alegre, 1987.

ASSMANN, Hugo (org.), Nicaragua Triunfa en la Alfabetización: documentos y testimonios de la Cruzada Nacional de Alfabetización, Ministério de Educación, Departamento Ecuménico de Investigaciones: San José, Costa Rica, 1981.

CARDENAL, Fernando, Objetivos de la Cruzada Nacional de Alfabetización, In: ASSMANN, Hugo (org.), op. Cit.

CASTAÑO, Bayardo Arce, La Educación y la Revolución, In: ASSMANN, Hugo (org.), Op. Cit. 
CHACON, Alícia. Revolução e alfabetização (entrevista). In: CARUSO, Raimundo C. Libre, Nicarágua Livre, Edição do autor: Florianópolis, 1980.

CORTÁZAR, Julio. Nicarágua: tão violentamente doce. Brasiliense: São Paulo, 1987. GALVÃO, Gilberto; MARCONDES, Pyr; JOHN, Liana; MONTIEL, Flávio. Nicarágua, Nicarágua, Grêmio Politécnico: São Paulo, 1980.

PIVA, Márcia Cruz; PIVA, Marco Antonio, Nicarágua: um povo e sua bistória (15521984), Paulinas: São Paulo, 1986.

YEVES, Enrique, La Contra: una guerra sucia, Ediciones B: Barcelona, 1990.

\section{The education as element of national reconstruction: the case of the Sandinist Nicaragua.}

\section{ABSTRACT}

The purpose of this article is to offer an analysis brief of the form with as the education can to consist of in element of reconstruction of an nation. Approach here the case of the National Alphabetization Crusade effectuated by Sandinist Government of Nicaragua afterwards his ascension at power in 1979. We detach here their objective, some aspects of the his organization, pointing still your essentials abstracts presupposeds.

Key-words: Latin América, Nicaragua, Sandinism, Education, Alphabetization. 